\title{
PD-CATALYZED C-C BOND FORMATION AS \\ A PERSPECTIVE ROUTE FOR DESIGN OF NEW BIOLOGICALLY ACTIVE $N^{6}$-SUBSTITUTED ADENOSINES
}

\author{
V.E. Oslovsky, A.A. Zenchenko, M.S. Drenichev
}

Engelhardt Institute of Molecular Biology, RAS, 119991, Russia, Moscow, Vavilov Str. 32.

DOI: 10.19163/MedChemRussia2021-2021-296

E-mail: vladimiroslovsky@gmail.com

It was recently found by our research group, that various analogs of natural nucleoside $N^{6}$-benzyladenosine containing different hydrophobic aromatic substituents at the $N^{6}$ position of adenine possess high antiviral activity against human enterovirus EV71 [1, 2]. The most potent and selective were derivatives modified with acetylene linker between amino group of adenine and phenyl group or containing fluorine atoms or trifluoromethyl group in phenyl ring.

In the present study we report on the synthesis of a number of new $\mathrm{N}^{6}$ substituted adenosines containing additional bulky hydrophobic substituents using Pd-catalyzed cross-coupling reactions of the carbon-carbon bond formation (Sonogashira and Suzuki reactions).

The compounds were prepared from $N^{6}$-propargyl- $N^{6}$-acetyl-2',3',5'-tri-Oacetyladenosine and as initial substrate using the Sonogashira coupling methodology with various iodobenzenes, or from $N^{6}$-(4-iodobenzyl)- $N^{6}$-acetyl-2',3',5'-tri-Oacetyladenosine in the reaction with terminal alkynes to obtain $N^{6}$-benzyladenosine derivatives containing the acetylenic linker between the phenyl ring and adenine moiety. Besides, N6-(4-iodobenzyl)-N6-acetyl-2',3',5'-tri-O-acetyladenosine was also used as starting substrate in the Pd-catalyzed Suzuki reaction with alkyl boronic acids to obtain $N^{6}$-benzyladenosine analogs with additional aromatic or aliphatic substituent connected to benzyl moiety. Subsequent removal of acetyl protecting groups affords the final nucleosides in good overall yields.
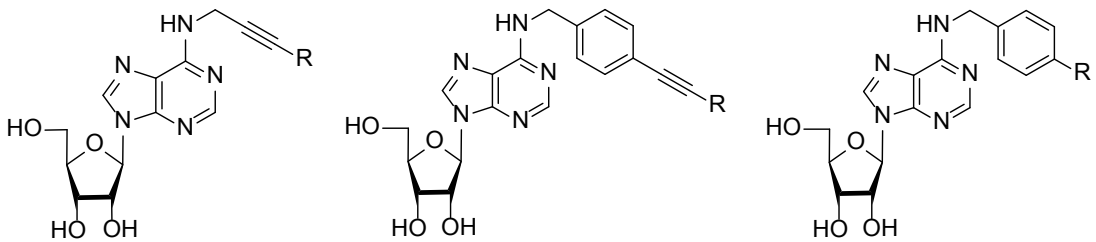

The synthesized compounds were evaluated for their antiviral activity for the panel of epidemiologically important RNA viruses, and it was found that some of these compounds have potential as inhibitors of virus replication in a mammalian bioassay.

This work was supported by Russian Federation President Program for Young Scientists (MK-1657.2021.1.4).

\section{References}

[1] M.S. Drenichev, V.E. Oslovsky, et al. Eur. J. Med. Chem. 2016, 111, 84-94.

[2] V.E. Oslovsky, M.S. Drenichev, et al. Molecules. 2017. 22.1219. 